\title{
Effects of Aged Stored Autologous Red Blood Cells on Human Endothelial Function
}

\author{
Michael G. Risbano ${ }^{1,2}$, Tamir Kanias ${ }^{2}$, Darrel Triulzi ${ }^{3}$, Chenell Donadee ${ }^{4}$, Suchitra Barge ${ }^{1}$, Jessica Badlam ${ }^{5}$, \\ Shilpa Jain ${ }^{6}$, Andrea M. Belanger ${ }^{7}$, Daniel B. Kim-Shapiro ${ }^{7}$, and Mark T. Gladwin ${ }^{1,2}$ \\ ${ }^{1}$ Division of Pulmonary Allergy and Critical Care Medicine, University of Pittsburgh and University of Pittsburgh Medical Center, \\ Pittsburgh, Pennsylvania; ${ }^{2}$ Pittsburgh Heart, Lung, Blood and Vascular Medicine Institute, ${ }^{3}$ Institute for Transfusion Medicine, \\ and ${ }^{4}$ Department of Critical Care Medicine, University of Pittsburgh, Pittsburgh, Pennsylvania; ${ }^{5}$ Division of Pulmonary Sciences and \\ Critical Care Medicine, University of Colorado, Denver, Colorado; 'Division of Hematology/Oncology, Women and Children's Hospital of \\ Buffalo, Buffalo, New York; and ${ }^{7}$ Department of Physics, Wake Forest University, Winston Salem, North Carolina
}

ORCID ID: 0000-0003-3334-7046 (M.G.R.).

\begin{abstract}
Rationale: A major abnormality that characterizes the red cell "storage lesion" is increased hemolysis and reduced red cell lifespan after infusion. Low levels of intravascular hemolysis after transfusion of aged stored red cells disrupt nitric oxide (NO) bioavailabity, via accelerated NO scavenging reaction with cell-free plasma hemoglobin. The degree of intravascular hemolysis post-transfusion and effects on endothelial-dependent vasodilation responses to acetylcholine have not been fully characterized in humans.
\end{abstract}

Objectives: To evaluate the effects of blood aged to the limits of Food and Drug Administration-approved storage time on the human microcirculation and endothelial function.

Methods: Eighteen healthy individuals donated $1 \mathrm{U}$ of leukopheresed red cells, divided and autologously transfused into the forearm brachial artery 5 and 42 days after blood donation. Blood samples were obtained from stored blood bag supernatants and the antecubital vein of the infusion arm. Forearm blood flow measurements were performed using strain-gauge plethysmography during transfusion, followed by testing of endotheliumdependent blood flow with increasing doses of intraarterial acetylcholine.

Measurements and Main Results: We demonstrate that aged stored blood has higher levels of arginase- 1 and cell-free plasma hemoglobin. Compared with 5-day blood, the transfusion of 42-day packed red cells decreases acetylcholine-dependent forearm blood flows. Intravascular venous levels of arginase- 1 and cell-free plasma hemoglobin increase immediately after red cell transfusion, with more significant increases observed after infusion of 42-day-old blood.

Conclusions: We demonstrate that the transfusion of blood at the limits of Food and Drug Administration-approved storage has a significant effect on the forearm circulation and impairs endothelial function.

Clinical trial registered with www.clinicaltrials.gov (NCT 01137656)

Keywords: nitric oxide; cell-free plasma hemoglobin; vasoreactivity; red cell transfusion; storage lesion

(Received in original form February 3, 2015; accepted in final form July 29, 2015)

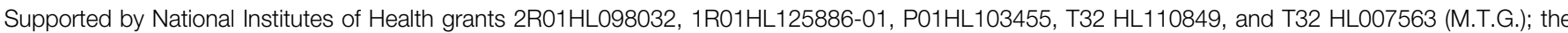
Institute for Transfusion Medicine (M.T.G.); and the Hemophilia Center of Western Pennsylvania (M.T.G).

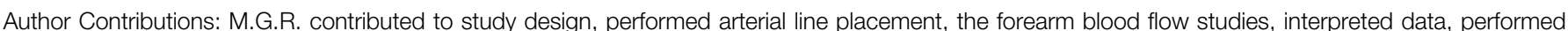

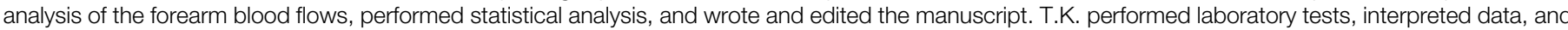

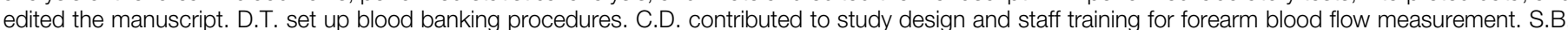

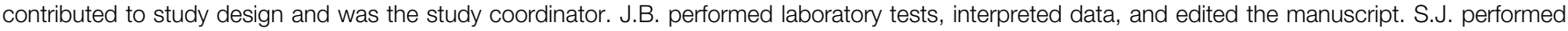

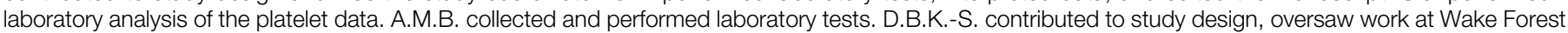
and edited the manuscript. M.T.G. contributed to study conception and design, provided laboratory support, data analysis, and edited the manuscript.

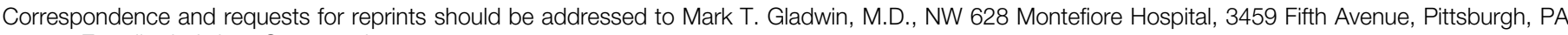
15213. E-mail: gladwinmt@upmc.edu

This article has an online supplement, which is accessible from this issue's table of contents at www.atsjournals.org

Am J Respir Crit Care Med Vol 192, Iss 10, pp 1223-1233, Nov 15, 2015

Copyright (C) 2015 by the American Thoracic Society

Originally Published in Press as DOI: 10.1164/rccm.201501-01450C on July 29, 2015

Internet address: www.atsjournals.org 


\section{At a Glance Commentary}

\section{Scientific Knowledge on the}

Subject: Prior studies evaluating the effects of transfusion of aged stored blood on human endothelial function have been limited by the noninvasive evaluation of vascular function.

\section{What This Study Adds to the}

Field: This study demonstrates that intraarterially infused red blood cells stored for 6 weeks, representing the limits of Food and Drug Administration-approved cold storage time, impairs endothelial function, as measured by the reduced forearm blood flow responses to acetylcholine, an endothelium NO

synthase-dependent vasodilator. These effects are associated with hemolysis-dependent release of cellfree plasma hemoglobin and arginase-1, both of which reduce the bioavailability of nitric oxide.

In the United States approximately 11 million units of red blood cells (RBCs) are transfused annually (1). The Food and Drug Administration (FDA) permits red cells to be stored up to 42 days before transfusion. In general, blood banks deliver the oldest units of red cells available to minimize blood product disposal.

As stored red cells age, complex biochemical, molecular, and metabolic alterations occur within the erythrocytes and storage medium leading to energetic compromise, characterized by ATP and DPG depletion, and loss of red cell membrane integrity (2). Subsequent decreased membrane deformability with increased fragility result in red cell hemolysis and release of red cell contents into the storage medium and into the intravascular space after transfusion. These changes in red cell structure and function during blood banking and storage have been referred to as the red cell storage lesion (3-8).

Observational studies have demonstrated an increased risk associated with red cell transfusions (9-11). This risk seems to be related to both the age and number of the units transfused. These findings have been observed in cohort studies and summarized in retrospective reports and meta-analyses, suggesting that the transfusion of older stored blood is associated with increased mortality $(12-14)$. As few as one to two RBC transfusions in susceptible patients, such as post-cardiopulmonary bypass surgery, have been associated with increased morbidity and mortality (15). This association of the age of blood and transfusion risk remains controversial, secondary to multiple confounding variables associated with transfusion of older units, including but not limited to the number of units, the recipient severity of illness, and changes in depletion of $\mathrm{O}$ antigen blood in the older unit pool.

Two recent large multicenter randomized clinical trials evaluating the effect of the age of red cells have been published $(16,17)$. Both studies failed to show a difference in primary outcomes between those transfused with fresher units and older units. However, in these studies the mean ages of older blood were only 22 and 28.3 days, respectively, and very few units of blood were transfused at the extreme limits of FDA-approved storage of 42 days (16-18). Thus, although transfusion of blood may increase risk $(12,13,15,19)$, whether this risk is compounded by storage age, especially at the limits of storage and in the setting of larger transfusion volumes, remains unclear (20-24).

The mechanisms by which blood transfusion may contribute to organ injury, dysfunction, and death remain uncertain. We have proposed that storage and posttransfusion hemolysis may cause endothelial dysfunction, mediated by the nitric oxide (NO) and L-arginine scavenging effects of cell-free plasma hemoglobin (CFPHb) and arginase-1, respectively. Multiple studies have supported this hypothesis in animal models, including the infusion of supernatant from aged banked red cells into rats, which resulted in vasoconstriction and hypertension (22). The transfusion of aged stored blood into dogs with Staphylococcus aureus pneumonia produced significant hemolysis that increased pulmonary pressures and mortality $(20,25)$. Similar findings have been demonstrated in mice, guinea pigs, and lambs (26-30).

Several recent studies have assessed vascular endothelial function in normal human volunteers after transfusion of autologous blood $(23,24,31)$. Berra and colleagues (31) reported that $1-\mathrm{U}$ transfusion of 40-day-aged red cells did not affect the reactive hyperemia index, a noninvasive measure of endothelial function, compared with transfusions of 3-day-aged red cells. In contrast, in a followup study the same group evaluated a single unit transfusion of autologous 40-daystored leukoreduced red cells into subjects with endothelial dysfunction and demonstrated increased post-transfusion levels of $\mathrm{CFPHb}$, NO consumption, and pulmonary artery pressures estimated by Doppler echocardiography $(23,31)$. Similarly, Neuman and colleagues (24) demonstrated that individuals with anemia receiving aged blood $(>21 \mathrm{~d})$ had evidence of endothelial dysfunction at 24 hours post-transfusion.

A limitation of all normal volunteer studies is the amount of autologous blood that can be safely transfused, which may be insufficient to affect vascular function systemically. In our studies described in detail next, we transfused fresh or aged stored autologous blood directly into the forearm brachial artery to expose the vessel to higher concentrations of transfused blood and model more significant transfusion exposures. We also tested endothelial function invasively, using infusions of acetylcholine (Ach), an endotheliumdependent vasodilator.

To test whether blood storage adversely affects vascular function, we enrolled normal volunteers to donate $1 \mathrm{U}$ of blood, which was leukoreduced and split in half. The volunteers then returned after approximately 1 week (range, 5-7 d) and 6 weeks (range, 40-42 d) for autologous transfusion of the blood into the forearm brachial artery. Immediately after the transfusion forearm endothelial function was tested with Ach infusions, which stimulate muscarinic receptors to activate endothelial NO synthesis and promote vasodilation. Compared with fresh blood we hypothesized that aged blood will demonstrate increased levels of hemolysis (resulting in increased CFPHb) measured in vivo after transfusion and in the stored blood supernatant; and reduce the vasodilatory response to intraarterial infusion of Ach, caused by direct scavenging of $\mathrm{NO}$ or oxidative inactivation of NO released from the endothelium.

\section{Methods}

The investigation enrolled a total of 18 healthy individuals at the University of Pittsburgh who were evaluated with 
strain-gauge plethysmography before and after autologous infusion of blood to evaluate forearm blood flow and vasodilatory responses to Ach (Table 1). Inclusion and exclusion criteria are reported the Methods section of the online supplement and in prior studies (22). The institutional review board at the University of Pittsburgh (\#PRO09100113) approved the study. Written informed consent was obtained from subjects. An NHLBI independent data, safety, and monitoring board monitored the study.

\section{Blood Donation}

Subjects donated $500 \mathrm{ml}$ of whole blood at the Central Blood Bank Donor Centers, Pittsburgh, to produce an apheresis unit. The blood was collected, processed, and leukoreduced according to current strict FDA and AABB requirements. Units were preserved in ADSOL solution, split into two equal volumes, and stored in a monitored temperature-controlled refrigerator at $1-6^{\circ} \mathrm{C}$ until needed, according to standard blood-banking practice. Half of the unit was stored for 5 days (range, 5-7) after donation and the second half-unit was stored until 42 days (range, 40-42) after donation.

\section{Blood Infusion}

The intravenous access procedure is described in the Methods section of the online supplement. On the first testing day (range, 5-7 d) the subjects received a $0.5 \mathrm{U}$ of blood, approximately $138 \pm 9 \mathrm{ml}$ (mean $\pm \mathrm{SD}$ ), transfused through a brachial artery line into the nondominant arm. On the second testing day (range, 40-42 d) the remainder of the unit was transfused. Blood was intraarterially transfused for a total duration ranging from 9 to 12 minutes. The volume of blood in each $0.5 \mathrm{U}$ influenced the duration of each transfusion. On average, the first transfusion of $140 \pm 16 \mathrm{ml}$ and second transfusion of $138 \pm 22 \mathrm{ml}$ lasted approximately $11.1 \pm 1.2$ and $10.9 \pm 1.4$ minutes, respectively. The sequentially increasing rates of transfusion were $5 \mathrm{ml}$ per minute for 2 minutes $(300 \mathrm{ml} / \mathrm{h})$,
Table 1. Baseline Subject Demographics for Forearm Blood Flow Study

\begin{tabular}{lc}
$\mathrm{n}$ & 18 \\
Sex & \\
$\quad$ Male & $11(61.1 \%)$ \\
$\quad$ Female & $7(38.9 \%)$ \\
Age, yr & $28.8 \pm 7.4$ \\
Race & \\
$\quad$ White & $12(73.4 \%)$ \\
Asian & $4(13.3 \%)$ \\
African American & $2(13.3 \%)$ \\
Hemoglobin, g/dl & $14.2 \pm 1.1$ \\
Creatinine, mg/dl & $0.9 \pm 0.2$ \\
Body mass index, $\mathrm{kg} / \mathrm{m}^{2}$ & $24.5 \pm 2.5$ \\
\hline
\end{tabular}

Laboratory studies were drawn before blood donation.

Values are expressed as mean $\pm \mathrm{SD}$.

$10 \mathrm{ml}$ per minute for 2 minutes $(600 \mathrm{ml} / \mathrm{h})$, and finally $15 \mathrm{ml}$ per minute until the unit was fully transfused $(900 \mathrm{ml} / \mathrm{h}$ ) (Figure 1). Before the study we confirmed that transfusion of red cells through a 20 -gauge brachial artery angiocatheter at infusion rates of 300,600, and $900 \mathrm{ml}$ per hour through the same infusion pump, filter, and tubing system did not produce

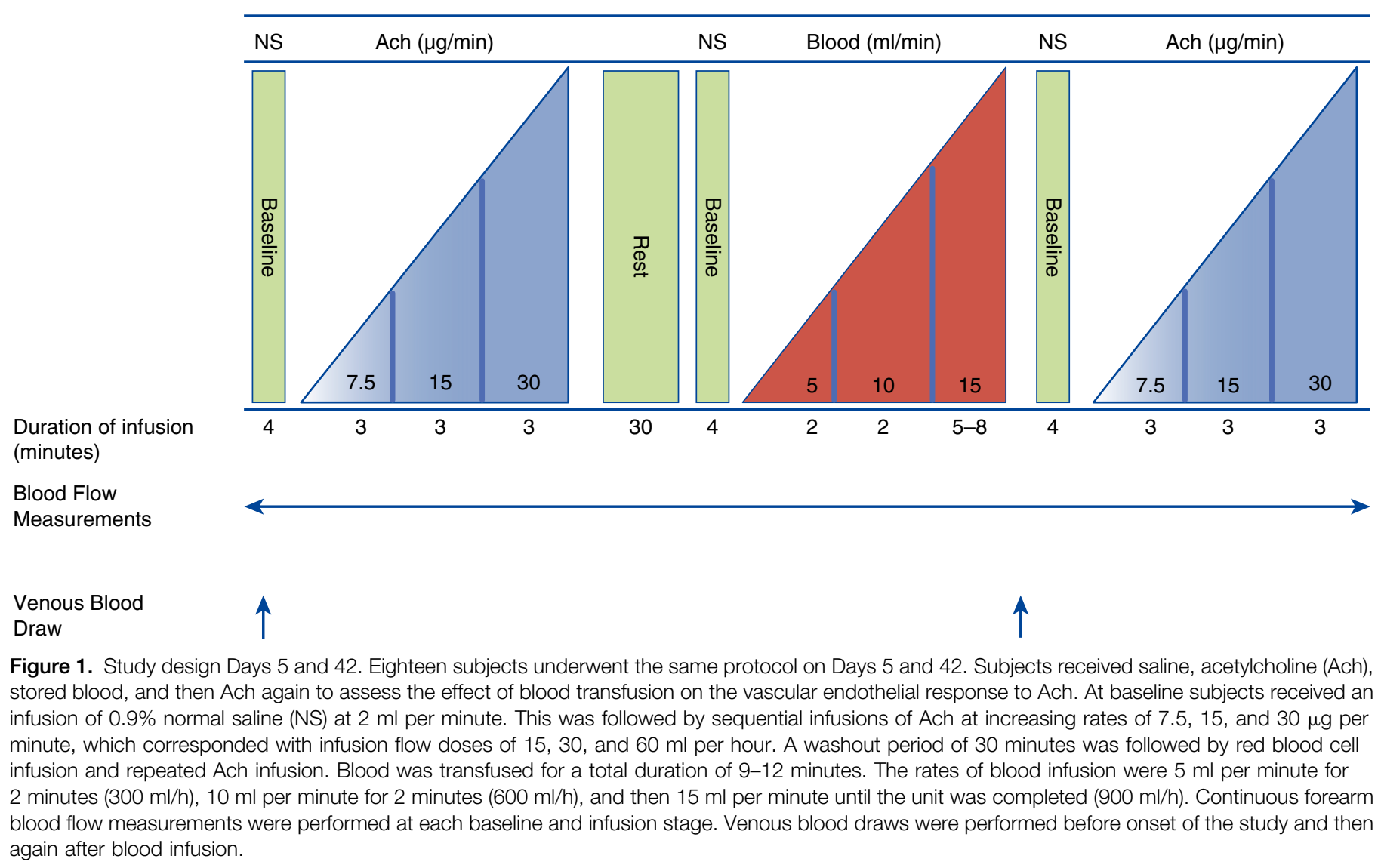


any artifactual hemolysis (see Figure E1 in the online supplement).

\section{Forearm Blood Flow Measurements}

Forearm blood flow measurements with venous occlusion strain-gauge plethysmography (Hokanson, Bellevue, WA) (32-34) are summarized in the Methods section of the online supplement.

\section{Study Design}

Figure 1 demonstrates the concentration, duration, and timing of the intraarterial infusions; the timing of venous blood sampling; and the forearm blood flow measurements. Eighteen participants underwent the same protocol on Days 5 and 42 with the exception of the age of blood infused. These subjects received sequential infusion of Ach, autologous RBC transfusion, and the repeat Ach infusion. Subjects refrained from drinking alcohol and caffeine for 8 hours and fasted overnight. Nonsteroidal antiinflammatory drugs were not permitted 1 week before to the study. All studies were performed in the morning to reduce circadian variation, in a quiet, temperature-controlled room.

Miochol-E powder (Novartis

Pharmaceuticals, Inc., Hanover, NJ) was used as the source of sterile Ach for use in this study. The University of Pittsburgh Medical Center Investigational Drug Service prepared the Ach solution for use. Ach acts as an endothelium-dependent vasodilator, stimulating endothelial cell muscarinic receptors to increase intracellular calcium and activate the endothelial NO synthase enzyme to synthesize NO from arginine, which relaxes vascular smooth muscle. Ach was continuously infused into the brachial artery with three sequentially increasing doses, each for 3 minutes at 7.5, 15, and $30 \mu \mathrm{g}$ per minute before and after the intraarterial infusion of autologous blood. These Ach doses corresponded to infusion rates of 15,30 , and $60 \mathrm{ml}$ per hour (Figure 1). Ach was infused with a normal saline carrier at decreasing rates of 105,90 , and $60 \mathrm{ml}$ per hour, respectively, to maintain a constant fluid rate of $120 \mathrm{ml}$ per hour to control for volume effects on blood flow measurements.

\section{Measurement of Blood Biomarkers from the Antecubital Vein after Transfusions}

Plasma levels of arginase-1 were measured by ELISA (Hycult Biotechnology BV, Uden, the Netherlands) according to the manufacturer's instructions and our previous publications (35). CFPHb was determined by human Hb ELISA (Human hemoglobin ELISA kit, Cat\#E88-135; Bethyl Laboratories, Montgomery, TX) according to the manufacturer's instructions; repeat CFPHb levels were confirmed by the conversion to cyanomethemoglobin with Drabkin reagent, as previously described (22).

\section{NO Consumption Assay}

The ability of CFPHb to scavenge $\mathrm{NO}$ was measured with a previously published and validated NO consumption assay using an NO ozone-based chemiluminescence analyzer (Sievers, Boulder, CO) (36).

\section{Preparation of Whole-Blood Platelet Samples}

See the Methods section of the online supplement for details.

\section{Blood Viscosity of Old Blood Compared with New Blood}

See the Methods section of the online supplement for details.

\section{Statistical Analysis}

We estimated that a total sample size of at least 15 subjects would be needed to achieve a $90 \%$ power to detect a $25 \%$ decrease in the forearm blood flow response to Ach in normal volunteers during the infusion of aged blood compared with fresh blood, with a type I error rate of 5\% (two-sided $\alpha$ ). Because of the intensity of the study requirements and risk of dropout, we screened 58 subjects and overenrolled into the study to ensure that at least 15 subjects completed the study.

Analysis was performed with Microsoft Office Excel 2007/2011 (Redmond, WA), and GraphPad Prism version 5 for Windows and 6 for Macintosh, (GraphPad Software, La Jolla, CA; www.graphpad.com). Subject venous and bag blood samples were tested for Gaussian distribution with the D'Agostino and Pearson omnibus normality test. Pairs of data sets were analyzed by either paired Student's $t$ test for normally distributed data or Wilcoxon matched-pairs signed rank test for data that were not normally distributed. The forearm blood flow data were evaluated by paired Student's $t$ test and repeated-measure oneway analysis of variance Tukey analysis for multiple comparisons post-test. Statistical significance was set at less than 0.05 .

\section{Results}

\section{Study Population}

Eighteen subjects completed the study as outlined in Table 1.

\section{Markers of Hemolysis Are Increased in Aged Stored Blood}

During standard RBC storage, products of RBC hemolysis accumulate in the ADSOL preservation solution (22). In our study, hemolysis products were measured in stored leukoreduced units of blood before infusions. As shown in Figure 2A, compared with fresh blood, aged blood demonstrated median levels (interquartile range) of CFPHb of 96.9 (48.9-114.1) versus $27.7(18.2-37.8) \mu \mathrm{M}(P<0.0001)$ increased levels of lactate dehydrogenase 255 (192-330) versus 133 (103-191) IU $(P=0.0001)$, and increased levels of plasma arginase-1 $334.9(192.2-509.6)$ versus 608.1 (334.2-688.9) ng/ml $(P=0.0003)$. The total hemoglobin in the stored blood did not change from Day 5 to 42 .

\section{NO Consumption Increases in Aged Stored Blood Units}

Normal human plasma reduces ferric heme $\left(\mathrm{Fe}^{+3}-\mathrm{Hb}\right)$ to ferrous heme $\left(\mathrm{Fe}^{+2}-\mathrm{Hb}\right)(36)$. We have shown that blood aged beyond 35 days contains at least $92 \%$ of the CFPHb in the ferrous oxyhemoglobin form (22). We now demonstrate that measured levels of NO consumption from the units of stored blood highly correlated with levels of CFPHb on both 5-day $(r=0.91 ; P<$ $0.0001)$ and 42 -day $(r=0.73 ; P=0.0006)$ blood (Figure 2B). This confirms that the $\mathrm{CFPHb}$ remains reduced in the ferrous oxyhemoglobin form $\left(\mathrm{Fe}^{+2}-\mathrm{O}_{2}\right)$, which is capable of reacting with $\mathrm{NO}$ via the dioxygenation reaction.

\section{Aged Blood Adversely Affects Endothelial Function as Measured by Forearm Blood Flow Responses to Ach Infusions}

Before and after transfusion of stored blood we infused Ach at 7.5, 15, and $30 \mu \mathrm{g}$ per minute. Our primary predefined endpoint of the study was the percentage change in Ach-induced blood flow after infusion of 42-day-aged stored blood compared with 5-day-aged stored blood. For each Ach 
A
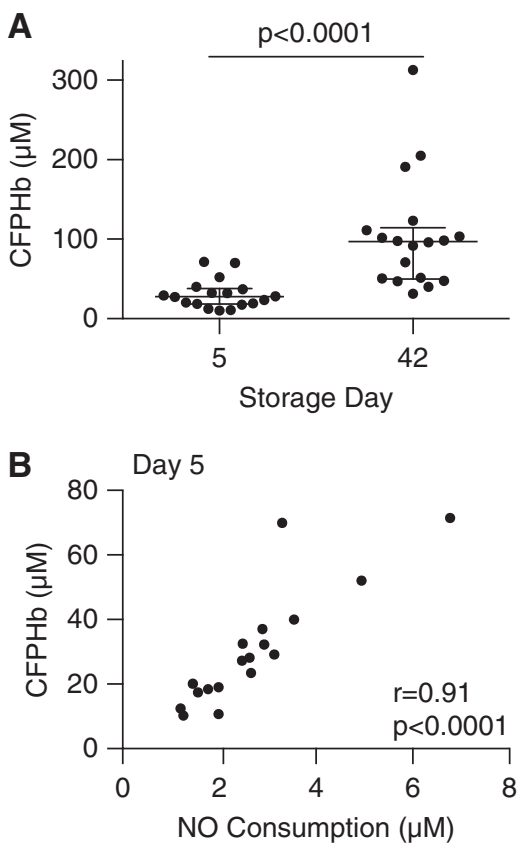
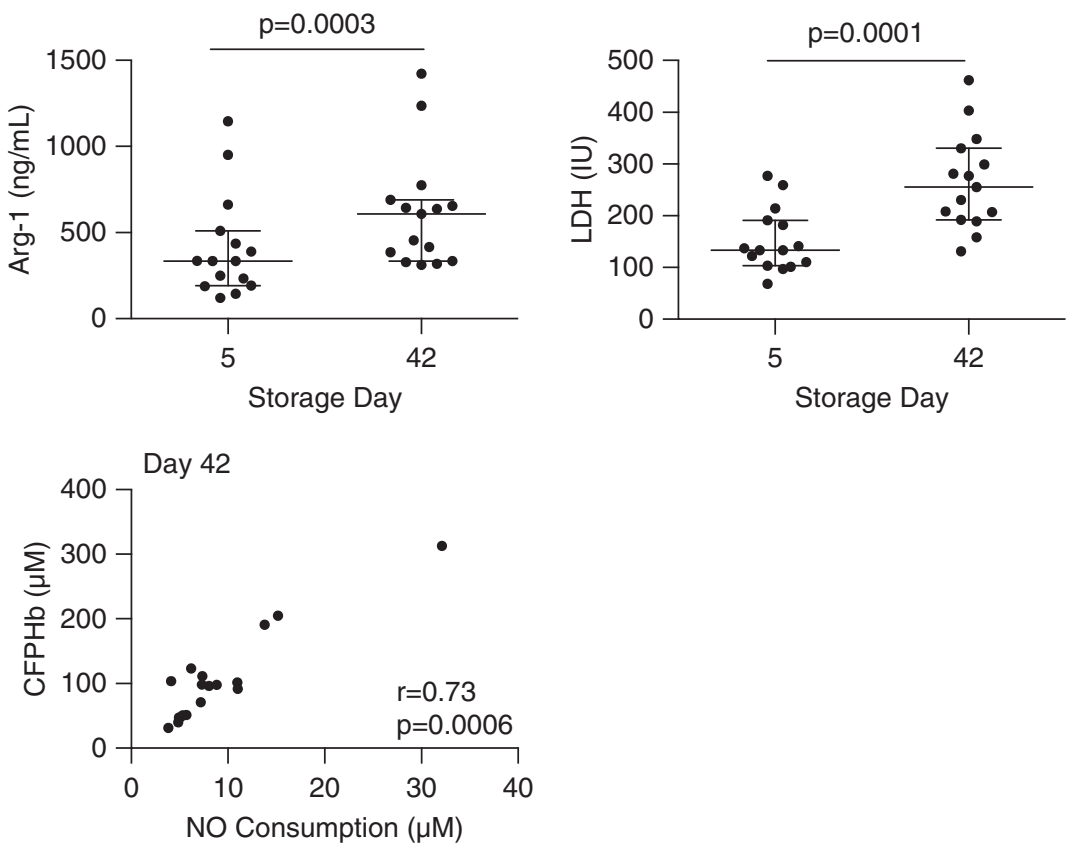

Figure 2. (A) Hemolysis in stored blood on storage Days 5 and 42. Scatter dot plots show the median (interquartile range) values for cell-free plasma hemoglobin (CFPHb), arginase-1 (Arg-1), and lactate dehydrogenase (LDH) for subjects. Values for CFPHb $(n=18), \operatorname{Arg}-1(n=15)$, and LDH $(n=15)$ were statistically significant when comparing levels at Day 5 of storage with Day 42 of storage, using Wilcoxon matched-pairs signed rank testing. (B) Correlation of nitric oxide (NO) consumption with CFPHb in stored blood for 5- and 42-day samples. Samples from the stored blood unit were obtained before transfusion for measure of analytes in the supernatant. NO consumption highly correlated with measured levels of CFPHb on Day $5(n=18)$ and Day $42(n=18)$, both of which are statistically significant.

infusion the \% change from baseline was significantly lower for post-RBC infusion on Day 42 compared with post-RBC infusion on Day 5. Both values for the absolute and \% change from baseline blood flows for Day 42 post-RBC infusion were lower with a $P$ value of less than 0.05 (Figure 3A). In fact, blood flow responses after transfusion of 42-day-old blood were lower than that of all other Ach infusions on Days 5 and 42 (Figure 3B). This demonstrates that a brief intraarterial infusion of aged stored blood has an effect on the forearm circulation that reduces the responsiveness to Ach, suggesting that aged stored blood impairs endothelial function.

There was no effect of fresh 5-daystored blood on the responses to Ach (Figure 3B), suggesting no adverse effect of fresh blood on endothelial function.

\section{Blood Transfusion Increases Shear Vasodilation during Infusion into an Artery}

Paradoxically, whereas the supernatant from the aged stored blood and the venous levels after transfusion had high levels of CFPHb and arginase-1, which was associated with impaired endothelial function after infusion, we observed an increase in blood flow acutely during the actual red cell transfusion into the brachial artery. The increase in forearm blood flow was associated with the rate of $\mathrm{RBC}$ infusion $(5,10$, and $15 \mathrm{ml} / \mathrm{min})$, such that the higher the rate of infusion increased the blood flow. We also observed a significant increase in the forearm blood flow on Day 42 compared with Day 5 stored blood, despite opposing effects on endothelial function (Figure 3C).

Interestingly, more than $90 \%$ of normal volunteers reported an increased sensation of "warmth" and "pins and needles" in the forearm during the infusion of 42-day blood, but not with infusion of fresh blood. These data are consistent with an increase in either shear-mediated or metabolic vasodilation of aged stored blood.

In support of this it has been reported that aged stored blood has increased viscosity compared with fresh blood (37). We tested the viscosity of 5- versus 42-daystored blood using a capillary viscometer (see the Methods section in the online supplement), and indeed found that the older blood had a viscosity that was $34.6 \%$ higher than that of fresh blood (Figure 4A). Because shear force is related to viscosity times flow, this is expected to almost double shear at all flows. These findings suggest a viscosity shear-mediated effect on blood flow. We also evaluated the effects of saline infusions into the brachial artery at different flow rates to determine if the rate of fluid infusion into the brachial artery affects shear-mediated vasodilation. As shown in Figure 4B, we observed a ratedependent increase in blood flow in response to saline, albeit to a lesser effect than observed with more viscous blood (Figure 3C). In aggregate these data support the hypothesis that aged stored blood infusions into the brachial artery exhibit acute shear-mediated vasodilation, whereas at the same time impair blood flow responses to Ach after infusion.

\section{Subject Venous Samples} Demonstrate Increased Intravascular Hemolysis after the Intraarterial Infusion of Blood

Immediately after the intraarterial infusion of red cells on Days 5 and 42, hemolysis markers were measured from the study arm 
A
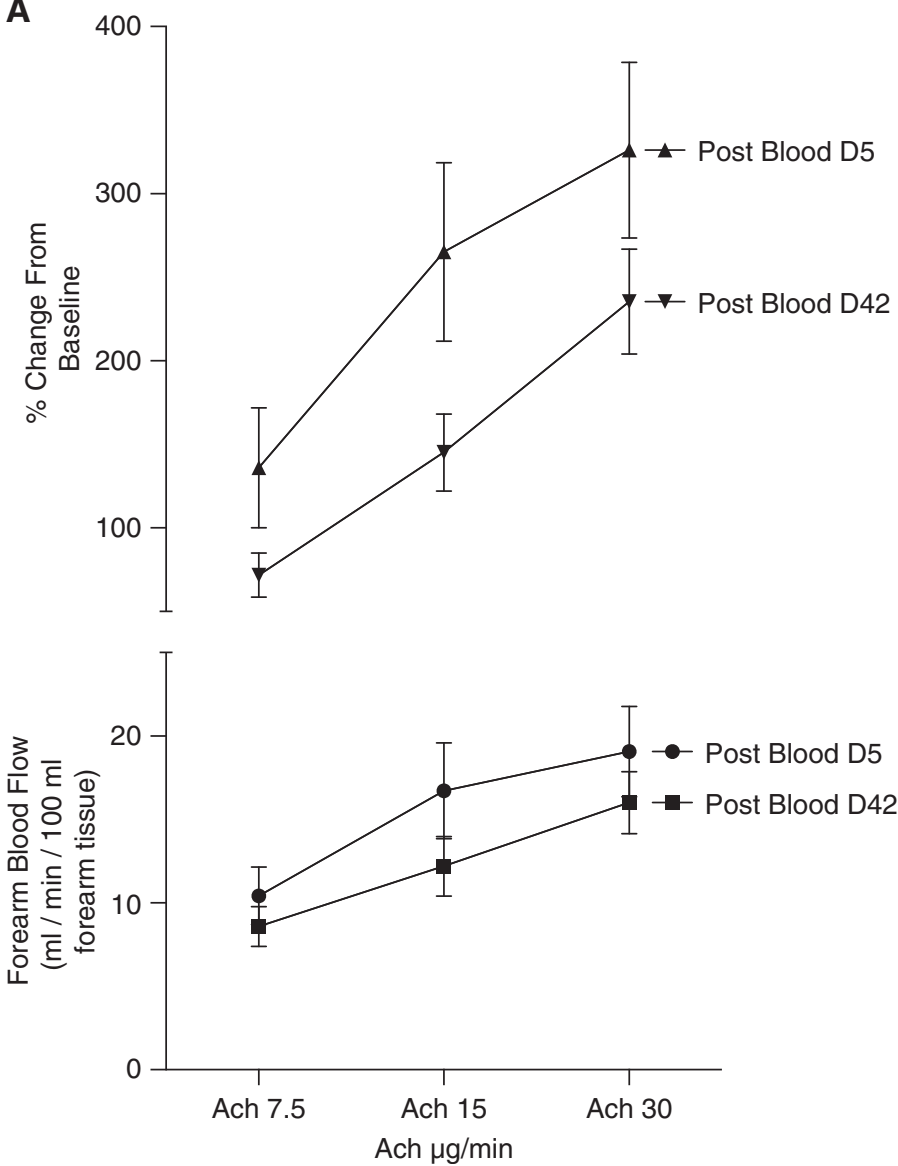

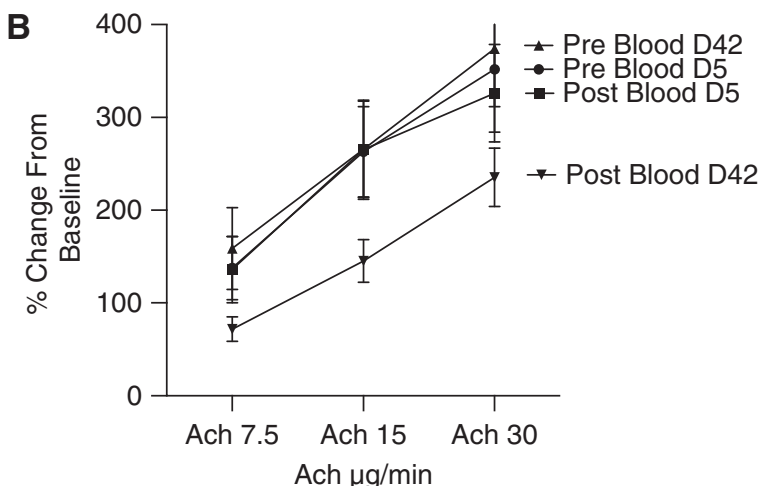

C
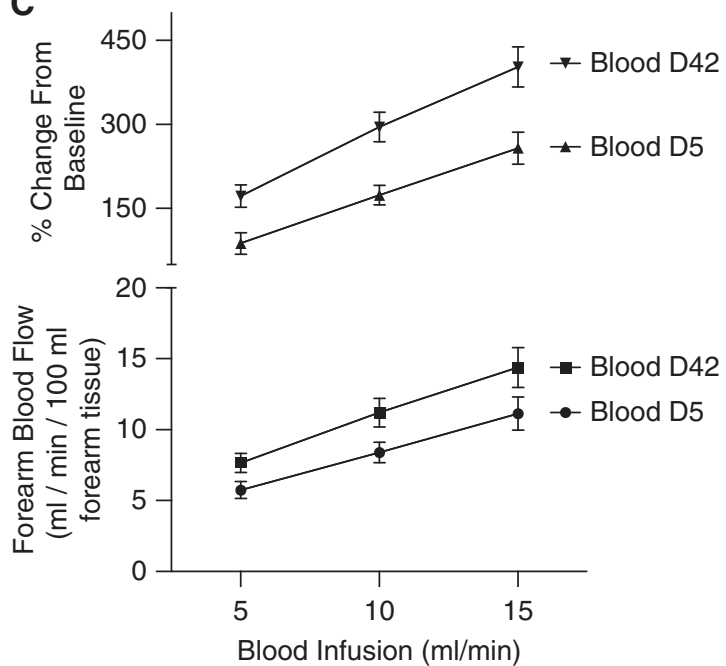

Figure 3. Forearm blood flow measurements. (A) Days 5 and 42 forearm blood flow acetylcholine (Ach) response postintraarterial autologous red blood cell (RBC) infusion. Days 5 and 42 forearm blood flows are expressed in absolute and \% change from baseline forearm blood flows. Compared with Day 5 measurements, the Ach response on Day 42 is reduced by both absolute and \% change from baseline values after the transfusion of aged blood. (B) Percent change in forearm blood flow caused by Ach infusion pre- and post-RBC infusion. Infusion of 42-day-old RBCs results in significantly reduced forearm blood flows measured by Ach response when compared with Day 5 pre- and post-RBC infusion and Day 42 pre-RBC infusion. Forearm blood flows are expressed as \% change from baseline forearm blood flows. (C) Forearm blood flows during autologous intraarterial RBC infusion. The blood flows, expressed in absolute and \% change from baseline forearm blood flows, are plotted against the rate of RBC infusion of Days 5 and 42 aged RBCs. The values for both absolute and \% change from baseline values are concordant, with a significantly increased flow of blood after the infusion of older RBCs.

vein while the upper arm-cuff was inflated to limit blood escape from the forearm circulation. This represents local forearm vasculature levels of hemolysis. The levels of CFPHb and arginase-1 were significantly increased pre- and post-blood infusion on Days 5 and 42, respectively (Figure 5). Median (interquartile range) CFPHb levels increased from 4.3 (1.5-12.0) to 7.9 (3.1-12.5) $\mu \mathrm{M}(P=0.18)$ on Days 5 and 6.5 $(2.2-8.1)$ to $10.8(5.6-14.8) \mu \mathrm{M}(P=0.04)$ on Day 42. Plasma arginase-1 increased from 31.2 (16.6-62.8) to 53.1 (23.9-103.1) $\mathrm{ng} / \mathrm{ml}(P=0.009)$ on Day 5 and 27.0 $(20.1-57.0)$ to $76.1(39.7-107.8) \mathrm{ng} / \mathrm{ml}$ $(P<0.0001)$ on Day 42. The total venous hemoglobin, aspartate aminotransferase, and lactate dehydrogenase values also increased after transfusion.

\section{Systemic Arterial Blood Pressures (Mean Arterial Pressures) Increase on Day 5 and Day 42 after the Infusion of Red Cells}

Five- and 42-day mean arterial pressures increased immediately after blood infusion from $($ mean \pm SD) $87.3 \pm 9.0$ to $89.6 \pm 8.9$ $\mathrm{mm} \mathrm{Hg}(P=0.039)$ and from $84.6 \pm 9.1$ to $88.6 \pm 9.7 \mathrm{~mm} \mathrm{Hg}(P=0.001)$, respectively (Figure 6). There was no associated increase in heart rate on either transfusion day. The pressor response was likely related to increased blood volume, $\mathrm{CFPHb}$, and/or arginase-1 release during red cell infusion, as previously demonstrated (22).

\section{Platelet Activation Was Not Increased after Red Cell Transfusion on Day 5 or Day 42}

Platelets are activated during red cell storage through adenosine diphosphate and $\mathrm{CFPHb}$ release, which enhances platelet activation by lowering NO bioavailability and stimulating purinurgic receptors (38). There was no observed effect of red cell transfusion on platelet activation, possibly related to the citrate preservative in the stored blood (see Figure E3). 

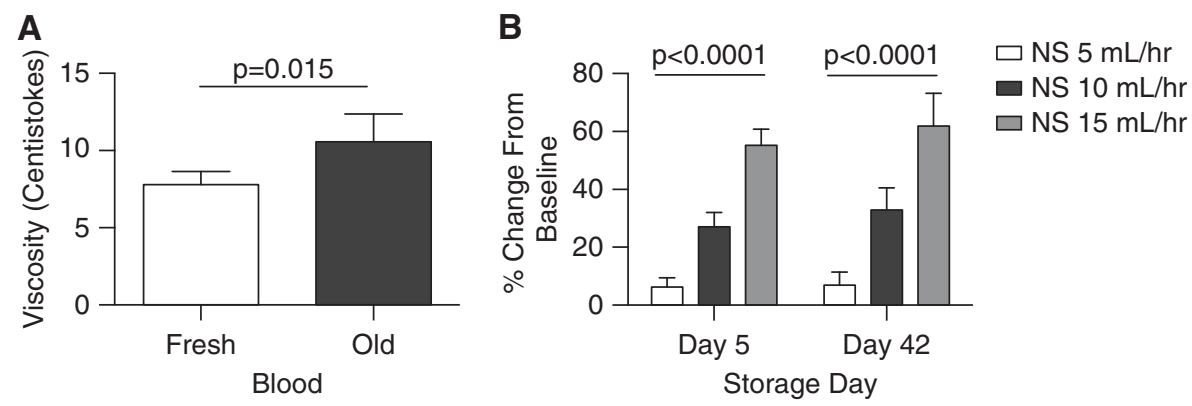

Figure 4. (A) Viscosities of fresh and aged red blood cells. Viscosity was found by multiplying the efflux time by the shear rate provided with the viscometer. The average viscosities for fresh and older blood were $7.8 \pm 0.8 \mathrm{cSt}$ and $10.5 \pm 1.8 \mathrm{cSt}$, respectively $(P=0.015)$. (B) Effects of saline infusions at different flow rates. The $\%$ change from baseline of flows for saline increased as the rate of flow increased at 5, 10, and $15 \mathrm{ml}$ per hour. The \% changes from baseline for saline at all infusion rates are lower than that of blood or acetylcholine infusions but do show that higher intraarterial infusion rates produce shear-related increases in blood flow. $\mathrm{cSt}=$ centistokes; NS = normal saline.

\section{Discussion}

This is the first study to invasively and directly assess human endothelialdependent vascular function using the intraarterial infusion of Ach before and after an autologous transfusion at the extremes of FDA red cell storage. We found significant effects of transfusion of aged stored blood, with increases in storage and posttransfusion hemolysis, increased plasma $\mathrm{NO}$ scavenging, and impaired endothelial function. We observed significant individual donor variability in the rate of storage hemolysis, suggesting donor-specific genetic factors in addition to storage time effects.

Our study used sensitive and specific measures of vascular endothelial function by infusing the endothelium-dependent vasodilator Ach coupled to blood flow assessments using strain-gauge plethysmography. We also exposed the forearm vasculature with a relatively larger transfusion exposure by infusing the blood directly into the brachial artery circulation. Prior studies in humans assessed vascular endothelial function by noninvasive measures of flow-mediated vasodilation after the systemic transfusion of $1 \mathrm{U}$ of packed RBCs (PRBCs) $(23,24,31)$.

Transfusion studies in normal volunteers are limited by the amount of RBCs that can be infused. Our invasive method of intraarterial transfusion aimed to address this shortcoming by delivery of blood into a smaller circulation volume and vascular bed. The intraarterial transfusion of 42-day $\mathrm{RBCs}$ into the forearm circulation attempted to model the intravascular effects of a more significant transfusion.

Our findings in the systemic circulation are consistent with data recently reported for the pulmonary circulation by Berra and colleagues (23) who demonstrated that the autologous transfusion of leukoreduced red cells stored for 40 days and transfused into subjects with endothelial dysfunction increased $\mathrm{CFPHb}, \mathrm{NO}$ consumption, and pulmonary artery pressures measured by Doppler echocardiography. The increased pulmonary artery pressures were ameliorated with inhaled NO, which oxidized the plasma hemoglobin to methemoglobin, inhibited NO consumption, and vasodilated the pulmonary circulation. Combined, both our and the Berra and colleagues (23) findings demonstrate that aged red cell infusions acutely increase the levels of CFPHb and are associated with decreases in NO-dependent blood flows and increased vasoconstriction.

The storage lesion refers to alterations within stored red cells resulting in multiple changes leading to a loss of membrane integrity, and release and accumulation of $\mathrm{CFPHb}$ and microparticles containing hemoglobin $(22,39,40)$. The reported levels of CFPHb have ranged between 28 and $593 \mu \mathrm{M}$ after 35 days of storage in citratephosphate-dextrose-adenine anticoagulant $(41,42)$. We demonstrate that the concentration of $\mathrm{CFPHb}$ from leukoreduced red cells aged for 42 days in ADSOL is $96.9 \mu \mathrm{M}$, which is consistent with our previously published data of

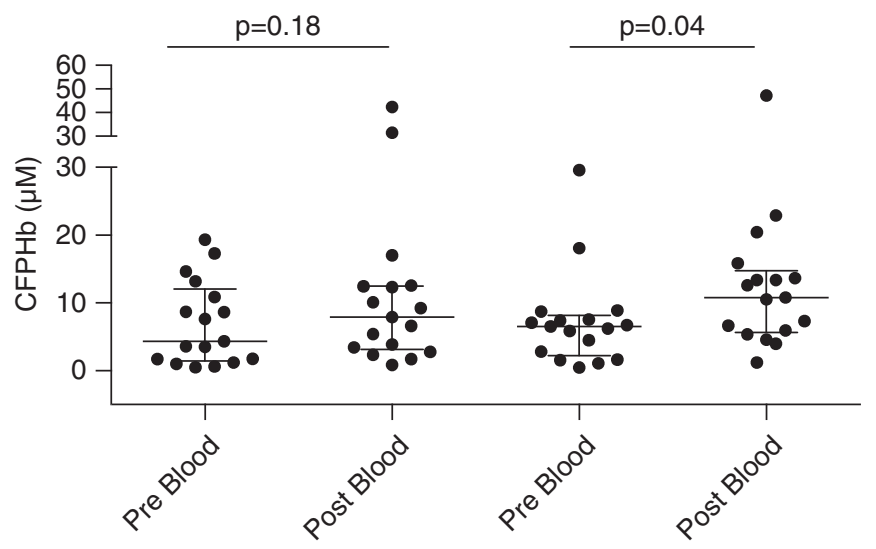

Day 5

Day 42

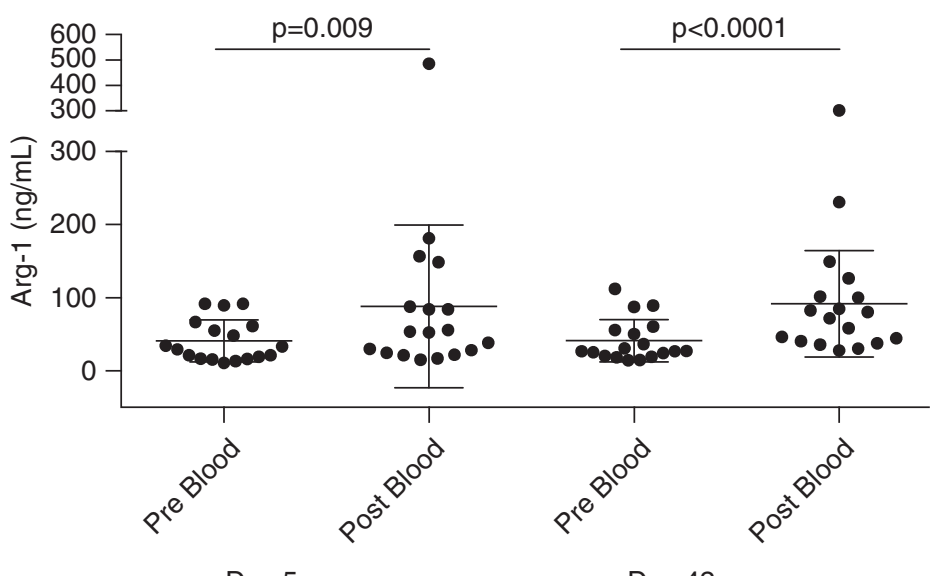

Day 5

Day 42

Figure 5. Venous samples for hemolysis before and after blood infusion. The median (interquartile range) plasma venous blood values for cell-free plasma hemoglobin (CFPHb) and arginase-1 (Arg-1) obtained on Days 5 and 42. Levels of CFPHb and Arg-1 are increased after red cell infusion. Wilcoxon matched-pairs signed rank testing was performed. 

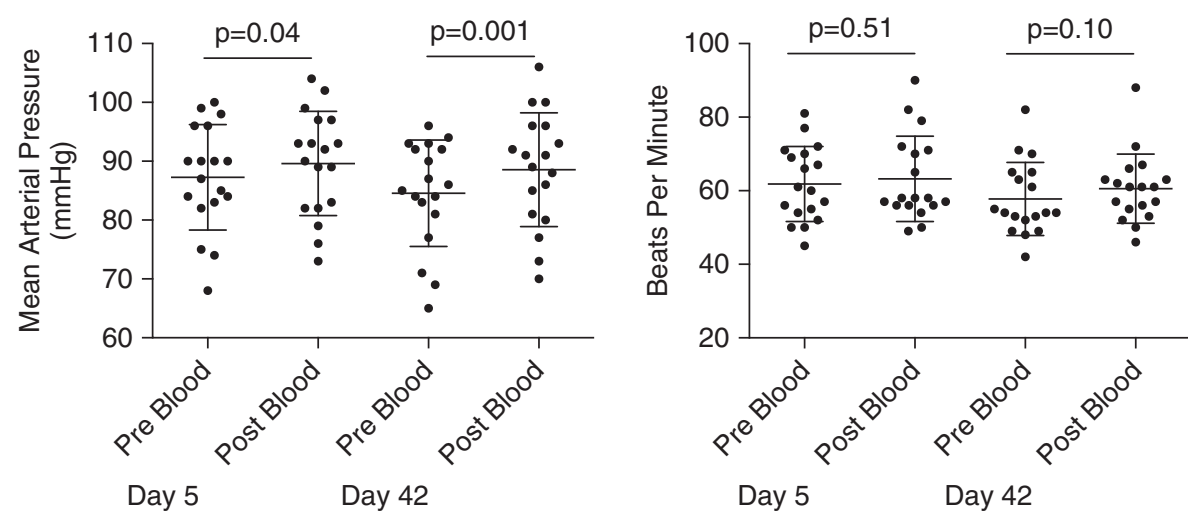

Figure 6. Mean arterial blood pressure and heart rate. Mean arterial pressures and heart rate values were obtained immediately pre- and post-red blood cell infusion. There is a statistically significant increase in systemic pressures post-blood infusion that was not demonstrated with heart rate, indicating that the mean arterial pressure response was not likely catecholamine driven. Values are expressed as mean (SD).

81-88 $\mu \mathrm{M}$ in nonleukoreduced blood (22). This suggests that there are limited differences in rates of hemolysis between leukoreduced and nonleukoreduced units of blood $(22,43)$.

The classic dioxygenation reaction shows that NO exposed to oxyhemoglobin results in the rapid consumption of NO, producing methemoglobin and nitrate. This near diffusion-limited fast reaction $\left(\mathrm{k}=10^{7}-10^{8} \mathrm{M}^{-1} \mathrm{~s}^{-1}\right)$ is irreversible and inactivates $\mathrm{NO}$ in blood.

$$
\begin{aligned}
\mathrm{HbFe}^{+2} & -\mathrm{O}_{2} \text { (oxyhemoglobin) } \\
& +\mathrm{NO} \rightarrow \mathrm{HbFe}^{+3} \text { (methemoglobin) } \\
& +\mathrm{NO}_{3}^{-} \text {(nitrate) }
\end{aligned}
$$

When hemoglobin is sequestered within the red cell membrane, NO is scavenged 1,000 times slower, compared with CFPHb (22). In our study we infused fresh and aged blood containing varying degrees of hemolysis measured in stored blood and measured within the vein of recently transfused subjects. We demonstrate that samples taken from the vein immediately after red cell infusion have elevated levels of CFPHb and arginase- 1 on Day 42 . We have previously shown that small amounts of $\mathrm{CFPHb}$ result in reduced NO bioavailability with levels as low as $1 \mu \mathrm{M}$ in kinetic models and $6 \mu \mathrm{M}$ in animal models $(32,43)$. The venous levels of CFPHb on Days 5 and 42 were 7.9 and $10.8 \mu \mathrm{M}$, respectively, which are higher than the levels previously shown to impair NO signaling in animals and in computational models. Patients experiencing a sickle-cell vasoocclusive crisis hemolyze red cells with CFPHb measured at $9.6 \mu \mathrm{M}(32,43)$. These values are similar to that of our measured $\mathrm{CFPHb}$ venous levels from Day 42. In trauma patients, massive transfusion can result in the transfusion of at least $10 \mathrm{U}$ of PRBCs in a 24-hour period (44). Such exposure to aged PRBCs could lead to over 20 times the exposure to $\mathrm{CFPHb}$ contributing to significant systemic effects on endothelial function.

Arginase is a critical component of the urea cycle that is released from erythrocytes during hemolysis and has been proposed to contribute to the development of pulmonary hypertension in patients with hemolytic anemias (45-47). Plasma levels of the arginase- 1 isoform strongly correlate with CFPHb $(22,45)$, because both are released from red cells during hemolysis (45). Increased levels of arginase catalyze the conversion of L-arginine to ornithine, reducing the bioavailability of arginine, the precursor to NO, contributing to endothelial dysfunction $(45,48)$. Our levels of arginase- 1 were significantly elevated by Day 42 of storage, but not to the extent of previously published levels by Donadee and coworkers (22): $608.1 \mathrm{ng} / \mathrm{ml}$ compared with $4,633 \mathrm{ng} / \mathrm{ml}$ at 39 days of storage. It is unclear if leukoreduction led to the difference in arginase-1 levels.

Red cell microparticles were not measured in this study, as in our prior publication (22). However, we previously documented the percentage of hemoglobin $\mathrm{CFPHb}$ that was contained in the form of microparticles. We found that $17.9 \pm 4.8 \%$ of plasma hemoglobin was contained in microparticles in $6 \mathrm{U}$ of 42-day-old stored blood centrifuged at $750 \times g$. Within the microparticles the hemoglobin concentration was $31.9 \pm 9.3 \mu \mathrm{mol} / \mathrm{L}$. This suggests that approximately $15 \%$ of the measured plasma hemoglobin in the current study is contained in microparticles. Similarly, Stapley and colleagues (21) demonstrated that microparticle levels increased during red cell storage, with the highest levels measured at 42 days of storage. Kinetic modeling demonstrated that there was a 40 -fold increase in red cell-dependent NO scavenging with 42-day blood compared with fresh blood.

Two large multicenter randomized clinical trials evaluating the effect of the age of red cells have been published $(16,17)$. The RECESS (Red Cell Storage Duration) study of 1,098 cardiac surgery patients in the United States randomized patients to red cells stored less than or equal to 10 days or greater than or equal to 21 days. The primary outcome was the change in multiorgan dysfunction score through Day 7. The ABLE (Age of BLood Evaluation) study of 2,420 intensive care unit patients in Canada randomized patients to red cells stored less than or equal to 7 days versus standard of care, approximately 22 days. The primary outcome was 90 -day mortality. Both studies failed to show a difference in primary outcomes between those transfused with fresher units and older units.

One of the limitations of the RECESS and ABLE studies is the mean ages of older blood were only 28.3 and 22 days, respectively. For ethical and technical reasons very few units of blood were transfused at the extreme limits of FDA storage of 42 days $(16,18)$. What the RECESS and ABLE studies have compared were the effects of fresh blood with the usual practice of standard-issue blood, not to the extremes of approved RBC storage as tested in our current study (18). We have previously demonstrated in Donadee and colleagues that after approximately 20 days of storage the degree of hemolysis and $\mathrm{CFPHb}$, free iron, and arginase release rises significantly and exponentially, so that at 35-42 days the hemolysis of aged blood would be maximal (22).

There are several important limitations in this study to highlight. The study represents a small sample size of healthy 
individuals and the transfused blood was autologous rather than allogeneic. Subjects had received blood intraarterially, which may affect forearm blood flow via shear affects, as described previously. However, this approach allowed for the exposure of the forearm microcirculation to a relatively high concentration of transfused blood. Additionally we were also unable to determine what degree the increased venous levels of CFPHb were a consequence of
$\mathrm{CFPHb}$ added by transfusion or caused by the immediate intravascular hemolysis of transfused RBCs. However, we have shown conclusively that there is minimal artifactual hemolysis of the stored blood infusion through our tubing, pumps, and filters (see Figure E1).

We were also limited to two transfusions at the extremes of cold storage. This was a highly technical study, requiring blood collection and processing, intraarterial blood infusions, arterial catheters, and the need to obtain FDA Investigational New Drug for use of Ach, and was focused on addressing the physiologic effects of blood at the limits of cold storage that are currently FDA approved. We were limited by the institutional review board in this extremely complex study in normal volunteers of autologous blood storage and transfusion to two infusions because the maximal blood we

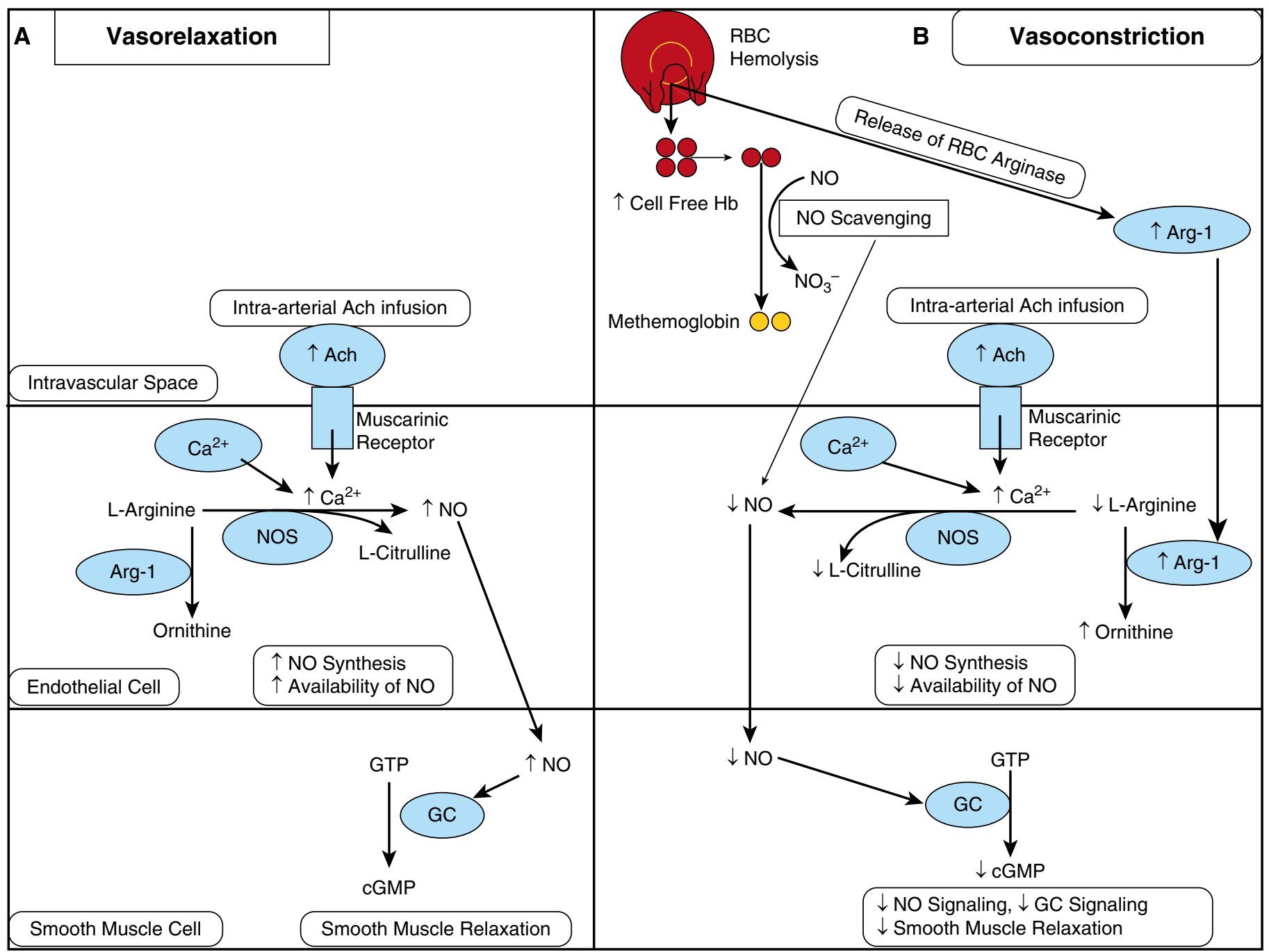

Figure 7. Model of the response to acetylcholine (Ach) in the absence and presence of red cell hemolysis. (A) In the absence of hemolysis, intravascular Ach infusion stimulates muscarinic receptors on the surface of endothelial cells to increase the influx of $\mathrm{Ca}^{2+}$. This stimulates nitric oxide synthase (NOS) activity to increase conversion of L-arginine to nitric oxide (NO), increasing NO synthesis and availability, which diffuses to adjacent smooth muscle cells. NO then stimulates guanylate cyclase (GC) activity in smooth muscle to increase conversion of guanosine triphosphate (GTP) to cyclic guanosine monophosphate (cGMP), resulting in smooth muscle relaxation. (B) In the presence of red cell hemolysis, hemoglobin and arginase-1 (Arg-1) are released from the red cell into the plasma. Cell-free plasma hemoglobin is released from hemolyzed red cells and scavenges available intravascular NO by the dioxygenation reaction. Decreased NO availability results in decreased NO signaling and decreased smooth muscle relaxation. Additionally, the release of Arg-1 from cellular hemolysis metabolizes L-arginine to ornithine, further decreasing availability of NO. In this hemolysis model, infusion of intravascular Ach is relatively ineffective because NO availability and synthesis are reduced, thereby decreasing the ability of smooth muscle to relax, or a relative vasoconstrictive effect. $\mathrm{RBC}=$ red blood cell. 
could collect was one large pheresis unit of $400-450 \mathrm{ml}$ of PRBC. We note in the data published in Donadee and colleagues (22) that after 20 days of storage the degree of hemolysis and hemoglobin, free iron, and arginase release increases significantly and exponentially, so that at Weeks 5-6 the risk would be greatest.

In summary, we demonstrate that human blood at the limits of approved cold storage time undergoes significant hemolysis and increases CFPHb and arginase-1 levels in the forearm circulation after transfusion. This results in both the scavenging of available $\mathrm{NO}$ and produces endothelial dysfunction, as directly assessed by observed reductions in the vasodilatory effect of intraarterial infusion of Ach (Figure 7). Thus, although recent clinical trials suggest that fresh blood has similar safety as blood stored to a mean of 22-28 days, the extreme last week of storage has not been evaluated with sufficient power. Our data confirm preclinical data and raise important questions about safety and pathophysiologic effects of transfused blood from the last week of cold storage.

Author disclosures are available with the text of this article at www.atsjournals.org.

Acknowledgment: The authors thank the University of Pittsburgh CTRC nursing staff for their expertise, patience, and tireless efforts during this study.

\section{References}

1. Wald ML. Blood industry shrinks as transfusions decline. New York Times 2014 August 22 [accessed 2015 Jun 22]; Business Day. Available from: http://www.nytimes.com/2014/08/23/business/bloodindustry-hurt-by-surplus.html?_r=0

2. Abdel-latif RG, Morsy MA, El-Moselhy MA, Khalifa MA. Sildenafil protects against nitric oxide deficiency-related nephrotoxicity in cyclosporine A treated rats. Eur J Pharmacol 2013;705:126-134

3. Card RT, Mohandas N, Perkins HA, Shohet SB. Deformability of stored red blood cells. Relationship to degree of packing. Transfusion 1982; 22:96-101.

4. Berezina TL, Zaets SB, Morgan C, Spillert CR, Kamiyama M, Spolarics Z, Deitch EA, Machiedo GW. Influence of storage on red blood cell rheological properties. J Surg Res 2002;102:6-12.

5. Card RT, Mohandas N, Mollison PL. Relationship of post-transfusion viability to deformability of stored red cells. Br J Haematol 1983;53: 237-240.

6. Haradin AR, Weed RI, Reed CF. Changes in physical properties of stored erythrocytes relationship to survival in vivo. Transfusion 1969;9:229-237.

7. Izzo P, Manicone A, Spagnuolo A, Lauta VM, Di Pasquale A, Di Monte D. Erythrocytes stored in CPD SAG-mannitol: evaluation of their deformability. Clin Hemorheol Microcirc 1999;21:335-339.

8. Bennett-Guerrero E, Veldman TH, Doctor A, Telen MJ, Ortel TL, Reid TS, Mulherin MA, Zhu H, Buck RD, Califf RM, et al. Evolution of adverse changes in stored RBCs. Proc Natl Acad Sci USA 2007;104: 17063-17068.

9. Hébert PC, Wells G, Blajchman MA, Marshall J, Martin C, Pagliarello G, Tweeddale M, Schweitzer I, Yetisir E. A multicenter, randomized, controlled clinical trial of transfusion requirements in critical care. Transfusion Requirements in Critical Care Investigators, Canadian Critical Care Trials Group. N Engl J Med 1999;340:409-417.

10. Offner PJ, Moore EE, Biffl WL, Johnson JL, Silliman CC. Increased rate of infection associated with transfusion of old blood after severe injury. Arch Surg 2002;137:711-716, discussion 716-717.

11. Cholette JM, Pietropaoli AP, Henrichs KF, Alfieris GM, Powers KS, Phipps R, Spinelli SL, Swartz M, Gensini F, Daugherty LE, et al. Longer RBC storage duration is associated with increased postoperative infections in pediatric cardiac surgery. Pediatr Crit Care Med 2015;16:227-235.

12. Koch CG, Li L, Sessler DI, Figueroa P, Hoeltge GA, Mihaljevic T, Blackstone $\mathrm{EH}$. Duration of red-cell storage and complications after cardiac surgery. N Engl J Med 2008;358:1229-1239.

13. Edgren G, Kamper-Jørgensen M, Eloranta S, Rostgaard K, Custer B, Ullum H, Murphy EL, Busch MP, Reilly M, Melbye M, et al. Duration of red blood cell storage and survival of transfused patients (CME). Transfusion 2010;50:1185-1195.

14. Wang D, Sun J, Solomon SB, Klein HG, Natanson C. Transfusion of older stored blood and risk of death: a meta-analysis. Transfusion 2012;52:1184-1195.

15. Paone G, Likosky DS, Brewer R, Theurer PF, Bell GF, Cogan CM, Prager RL. Transfusion of 1 and 2 units of red blood cells is associated with increased morbidity and mortality. Ann Thoracic Surg 2014;97:87-93; discussion 93-94.
16. Lacroix J, Hébert PC, Fergusson DA, Tinmouth A, Cook DJ, Marshall JC, Clayton L, Mclntyre L, Callum J, Turgeon AF, et al.; ABLE Investigators; Canadian Critical Care Trials Group. Age of transfused blood in critically ill adults. N Engl J Med 2015;372: $1410-1418$

17. Steiner ME, Ness PM, Assmann SF, Triulzi DJ, Sloan SR, Delaney M, Granger S, Bennett-Guerrero E, Blajchman MA, Scavo V, et al. Effects of red-cell storage duration on patients undergoing cardiac surgery. N Engl J Med 2015;372:1419-1429.

18. Lacroix J, Hébert P, Fergusson D, Tinmouth A, Blajchman MA, Callum J, Cook D, Marshall JC, McIntyre L, Turgeon AF; ABLE study group. The Age of Blood Evaluation (ABLE) randomized controlled trial: study design. Transfus Med Rev 2011;25:197-205.

19. Horvath KA, Acker MA, Chang H, Bagiella E, Smith PK, Iribarne A, Kron $\mathrm{IL}$, Lackner $\mathrm{P}$, Argenziano M, Ascheim DD, et al. Blood transfusion and infection after cardiac surgery. Ann Thorac Surg 2013;95: 2194-2201.

20. Wang D, Cortés-Puch I, Sun J, Solomon SB, Kanias T, Remy KE, Feng J, Alimchandani M, Quezado M, Helms C, et al. Transfusion of older stored blood worsens outcomes in canines depending on the presence and severity of pneumonia. Transfusion 2014;54: 1712-1724.

21. Stapley R, Owusu BY, Brandon A, Cusick M, Rodriguez C, Marques MB, Kerby JD, Barnum SR, Weinberg JA, Lancaster JR Jr, et al. Erythrocyte storage increases rates of $\mathrm{NO}$ and nitrite scavenging: implications for transfusion-related toxicity. Biochem $J$ 2012;446: 499-508.

22. Donadee C, Raat NJ, Kanias T, Tejero J, Lee JS, Kelley EE, Zhao X, Liu $\mathrm{C}$, Reynolds H, Azarov I, et al. Nitric oxide scavenging by red blood cell microparticles and cell-free hemoglobin as a mechanism for the red cell storage lesion. Circulation 2011;124:465-476.

23. Berra L, Pinciroli R, Stowell CP, Wang L, Yu B, Fernandez BO, Feelisch $M$, Mietto C, Hod EA, Chipman D, et al. Autologous transfusion of stored red blood cells increases pulmonary artery pressure. $A m \mathrm{~J}$ Respir Crit Care Med 2014;190:800-807.

24. Neuman R, Hayek S, Rahman A, Poole JC, Menon V, Sher S, Newman JL, Karatela S, Polhemus D, Lefer DJ, et al. Effects of storage-aged red blood cell transfusions on endothelial function in hospitalized patients. Transfusion 2015;55:782-790.

25. Solomon SB, Wang D, Sun J, Kanias T, Feng J, Helms CC, Solomon MA, Alimchandani M, Quezado M, Gladwin MT, et al. Mortality increases after massive exchange transfusion with older stored blood in canines with experimental pneumonia. Blood 2013;121: 1663-1672.

26. Baron DM, Beloiartsev A, Nakagawa A, Martyn T, Stowell CP Malhotra R, Mayeur C, Bloch KD, Zapol WM. Adverse effects of hemorrhagic shock resuscitation with stored blood are ameliorated by inhaled nitric oxide in lambs. Crit Care Med 2013;41:2492-2501.

27. Lei C, Yu B, Shahid M, Beloiartsev A, Bloch KD, Zapol WM. Inhaled nitric oxide attenuates the adverse effects of transfusing stored syngeneic erythrocytes in mice with endothelial dysfunction after hemorrhagic shock. Anesthesiology 2012;117: 1190-1202. 
28. Yu B, Lei C, Baron DM, Steinbicker AU, Bloch KD, Zapol WM. Diabetes augments and inhaled nitric oxide prevents the adverse hemodynamic effects of transfusing syngeneic stored blood in mice. Transfusion 2012;52:1410-1422.

29. Baron DM, Yu B, Lei C, Bagchi A, Beloiartsev A, Stowell CP, Steinbicker AU, Malhotra R, Bloch KD, Zapol WM. Pulmonary hypertension in lambs transfused with stored blood is prevented by breathing nitric oxide. Anesthesiology 2012;116:637-647.

30. Baek JH, D'Agnillo F, Vallelian F, Pereira CP, Williams MC, Jia Y, Schaer DJ, Buehler PW. Hemoglobin-driven pathophysiology is an in vivo consequence of the red blood cell storage lesion that can be attenuated in guinea pigs by haptoglobin therapy. J Clin Invest 2012; 122:1444-1458.

31. Berra L, Coppadoro A, Yu B, Lei C, Spagnolli E, Steinbicker AU, Bloch KD, Lin T, Sammy FY, Warren HS, et al. Transfusion of stored autologous blood does not alter reactive hyperemia index in healthy volunteers. Anesthesiology 2012;117:56-63.

32. Reiter CD, Wang X, Tanus-Santos JE, Hogg N, Cannon RO III, Schechter AN, Gladwin MT. Cell-free hemoglobin limits nitric oxide bioavailability in sickle-cell disease. Nat Med 2002;8: 1383-1389.

33. Gladwin MT, Schechter AN, Ognibene FP, Coles WA, Reiter CD, Schenke WH, Csako G, Waclawiw MA, Panza JA, Cannon RO III. Divergent nitric oxide bioavailability in men and women with sickle cell disease. Circulation 2003;107:271-278.

34. Cosby K, Partovi KS, Crawford JH, Patel RP, Reiter CD, Martyr S, Yang BK, Waclawiw MA, Zalos G, Xu X, et al. Nitrite reduction to nitric oxide by deoxyhemoglobin vasodilates the human circulation. Nat Med 2003;9:1498-1505.

35. Janka JJ, Koita OA, Traoré B, Traoré JM, Mzayek F, Sachdev V, Wang X, Sanogo K, Sangaré L, Mendelsohn L, et al. Increased pulmonary pressures and myocardial wall stress in children with severe malaria. $J$ Infect Dis 2010;202:791-800.

36. Wang X, Tanus-Santos JE, Reiter CD, Dejam A, Shiva S, Smith RD, Hogg N, Gladwin MT. Biological activity of nitric oxide in the plasmatic compartment. Proc Natl Acad Sci USA 2004;101: 11477-11482.
37. Daly A, Raval JS, Waters JH, Yazer MH, Kameneva MV. Effect of blood bank storage on the rheological properties of male and female donor red blood cells. Clin Hemorheol Microcirc 2014;56:337-345.

38. Helms CC, Marvel M, Zhao W, Stahle M, Vest R, Kato GJ, Lee JS, Christ G, Gladwin MT, Hantgan RR, et al. Mechanisms of hemolysis-associated platelet activation. J Thromb Haemost 2013;11:2148-2154.

39. Gao Y, Lv L, Liu S, Ma G, Su Y. Elevated levels of thrombin-generating microparticles in stored red blood cells. Vox Sang 2013;105:11-17.

40. Xiong Z, Cavaretta J, Qu L, Stolz DB, Triulzi D, Lee JS. Red blood cell microparticles show altered inflammatory chemokine binding and release ligand upon interaction with platelets. Transfusion 2011;51:610-621.

41. Latham JT Jr, Bove JR, Weirich FL. Chemical and hematologic changes in stored CPDA-1 blood. Transfusion 1982;22:158-159.

42. AuBuchon JP, Estep TN, Davey RJ. The effect of the plasticizer di-2ethylhexyl phthalate on the survival of stored RBCs. Blood 1988;71: 448-452.

43. Jeffers A, Gladwin MT, Kim-Shapiro DB. Computation of plasma hemoglobin nitric oxide scavenging in hemolytic anemias. Free Radic Biol Med 2006;41:1557-1565.

44. Sharpe JP, Weinberg JA, Magnotti LJ, Croce MA, Fabian TC. Toward a better definition of massive transfusion: focus on the interval of hemorrhage control. J Trauma Acute Care Surg 2012;73:1553-1557.

45. Morris CR, Kato GJ, Poljakovic M, Wang X, Blackwelder WC, Sachdev V, Hazen SL, Vichinsky EP, Morris SM Jr, Gladwin MT. Dysregulated arginine metabolism, hemolysis-associated pulmonary hypertension, and mortality in sickle cell disease. JAMA 2005;294:81-90.

46. Morris CR, Poljakovic M, Lavrisha L, Machado L, Kuypers FA, Morris SM Jr. Decreased arginine bioavailability and increased serum arginase activity in asthma. Am J Respir Crit Care Med 2004;170: 148-153.

47. Morris CR, Kuypers FA, Kato GJ, Lavrisha L, Larkin S, Singer T, Vichinsky EP. Hemolysis-associated pulmonary hypertension in thalassemia. Ann N Y Acad Sci 2005;1054:481-485.

48. Gladwin MT, Sachdev V, Jison ML, Shizukuda Y, Plehn JF, Minter K, Brown B, Coles WA, Nichols JS, Ernst I, et al. Pulmonary hypertension as a risk factor for death in patients with sickle cell disease. N Engl J Med 2004;350:886-895. 